\title{
Beitrag zur pathologischen Anatomie der Thränensackerkrankungen.
}

\author{
Von \\ Dr. E. Hertel \\ Privatdocenten und I. Assistenten der Jenaer Augenklinik. \\ Hierzu Tafel I-II, Figur 1-9. \\ (Aus der Jenaer Augenklinik.)
}

In den letzten sechs Jahren wurden in der Jenaer Augenklinik 52 Exstirpationen des Thränensackes ausgeführt. Das dadurch gewonnene, zum Theil sehr interessante Material wurde mir von meinem hochverehrten Chef Herrn Prof. Wagenmann zur Bearbeitung gütigst überlassen, wofür ich ihm auch an dieser Stelle meinen verbindlichsten Dank aussprechen möchte.

Es vertheilten sich die 52 Thränensackexstirpationen auf 43 Patienten, von denen 34 einseitig, 9 doppelseitig operirt wurden. Die Patienten gehörten fast ausnahmslos der arbeitenden Klasse an, in einer Altersgrenze von 3070 Jahren. Nur fünf $\mathrm{Mal}$ wurde die Exstirpation bei Kindern ausgeführt, ron denen das jüngste 8 , das älteste 14 Jahre zählte.

In Uebereinstimmung mit früheren Angaben von $R$. Schirmer (1), Fuchs (2) u. A., waren auch bei uns viel mehr weibliche Individuen von der Thränensackerkrankung befallen als männliche: von den 43 operirten Patienten waren 28 weiblichen Geschlechtes, also mehr als die Hälfte. Einen Grund dafür vermochte ich nicht zu finden. 
Die Indicationsstellung zur Exstirpation bewegte sich im Wesentlichen in den Grenzen, die seiner Zeit Schreiber (2), später Kuhnt(4) und Crermak(5) genauer angegeben haben. In der bei Weitem grössten Mehrzahl der Fälle handelte es sich um Jahre lang bestehende chronische Thränensackblennorrhoen mit Ektasie des Sackes.

In rielen dieser Fälle war vor der Radikaloperation versucht worden, ducch Sondirungen und nachfolgenden adstringirenden oder desinficirenden Durchspülungen des Thränenschlauches das Thränensackleiden zu bessern, doch nur selten mit Erfolg. Und auch bei den wenigen, bei denen thatsächlich eine Besserung nach einer längeren Sondenund Durchspullungscur zu verzeichnen war, trat oft nach einiger Zeit ein Recidiv auf, welches nun die Exstirpation des Sackes doch noch nöthig machte. Die anatomischen Veränderungen waren eben gerade bei diesen chronischen Eiterungen mit Ektasie des Sackes, wie später noch gezeigt wird, $\mathrm{zu}$ hochgradig, als dass sie einer conservativen Therapie hätten zugängig sein können.

Ferner wurden in einer Reihe von Fällen chronischer Thränensackerkrankung mit eitriger oder schleimigeitriger Secretion die Exstirpation vorgenommen, auch ohne dass eine Ektasie des Sackes sich hätte nachweisen lassen, jedoch nur dann, wenn durch länger anhaltende Sonden- und Durchspiilungscur sich eine dauernde Besserung oder Beseitigung des Leidens nicht erzielen liess.

In drei Fällen wurde die Indication lediglich durch die enorme Ektasie des Sackes abgegeben. Das Secret war dünnflüssig, aber sehr reichlich. Die Thränensackgegend prominirte ausserordentlich stark, die Haut über derselben erschien dünner. In einem Falle hing der ektatische Sack wie eine Cyste iber den Rand des knöchernen Canales nach unten. 
Beitrag zur patholog. Anatomie der Thränensackerkrankungen. 23

In Fällen, in welchen der Eiterungsprocess zu Fistelbildung nach aussen geführt hatte, wurde die Totalexstirpation nur ausgeführt, wenn keinerlei Entzündungserscheinungen Seitens der Umgebung des Sackes bestanden. War letzteres der Fall, so wurde der Sack durch Incision eröffnet und mit dem scharfen Löffel möglichst die erkrankte Schleimhaut entfernt.

Auch wegen Trberculose des Thränensackes mussten Exstirpationen vorgenommen werden.

Schliesslich gaben auch am Bulbus vorzunehmende Operationen oder gleichzeitig bestehende Hornhautgeschwüre Veranlassung zur Exstirpation des erkrankten Thränensackes.

Doch möchte ich betonen, dass die letzte Indication nicht so streng gehandhabt wurde wie von Czermak (l. c.) und noch mehr von Kuhnt (l. c.), welcher bei bestehenden Hornhautgeschwüren oder vor Bulbusoperationen oder bei frischen Verletzungen sogar ,in relativ frischen Fällen von Dacryocystitis" zur Exstirpation schreitet.

Nur bei vier von unseren Patienten wurde bei gleichzeitig bestehendem Hornhautgeschwür der erkrankte Thränensack sofort nach der Aufnahme in die Klinik exstirpirt. Es bestand hier stets eine starke Ekktasie mit reichlicher Eiterung. In sieben weiteren Fällen dagegen, in welchen ebenfalls Hornhautgeschwiire entstanden waren, wurde, da die Ektasie nur sehr gering oder gar nicht vorhanden war, zuerst conservativ verfahren, wie oben angegeben. Als die Ulcera dann abgeheilt waren, die Thränensackerkrankungen aber noch fortbestanden, wurde die Exstirpation noch nachträglich ausgeführt. Dass übrigens die primäre Exstirpation des Thränensackes ein Weiterschreiten des Uleus nicht aufzuhalten braucht, geht aus zwei you uns beobachteten Fällen hervor, in denen die Hornhautgeschwüre trotz der Exstirpation der Thränensäcke ausserordentlich progressiv blieben. 
Wegen Staar- oder sonstigen Bulbusoperationen wurde in fünf Fällen die primäre Thränensackexstirpation ausgeführt. Dem gegenüber stehen aber eine Reihe von Fällen, in denen das Thränenleiden durch conservative Behandlung vorher gebessert, oder nahezu beseitigt werden konnte und in denen die vorgenommenen Operationen ohne jede Complication verliefen. Einmal wurde nach einer gut ver* lavfenen Extraction die Thränensackexstirpation noch nachträglich ausgeführt.

Das Operationsverfahren, welches in unseren Fällen von Thränensackexstirpationen meist angewendet wurde, war kurz Folgendes:

Unter leichtem Zug nach der Nase wurde die Haut iiber der Thränensackgegend gespannt. Es trat dadurch das Ligamentum intemum ziemlich deutlich hervor. Die Schnittrichtung wurde nun bestimmt durch die Grenze zwischen innerem und mittlerem Drittel des Ligamentes und durch die Mitte zwischen Kinn und Kieferwinkel. Der Schnitt begann etwa $1-1 \frac{1 / 2}{\mathrm{~cm}}$ oberhalb des Ligamentes, erstreckte sich circa $2 \mathrm{~cm}$ unter dasselbe und wurde zuuächst nur durch die Haut geführt. Dann wurde das Ligamentum rom Assistenten am lateralen Ende fest gefasst. Der Operateur durchtrennte vorsichtig mit flachen Schnitten die obersten Schichten desselben und die den Thränensack vorn einhïllende Fascie. Sodann wurde der Sack von allen aufliegenden Muskeln und Bindegewebe frei präparirt. Auch die Loslosung vom Periost (medial) gelang meist leicht mit stumpfen Instrumenten, während man bei der Abtrennung von dem lateral ansitzenden Gewobe ohne Messer und Scheere oft nicht auskam. Sodann wurde auch die Thränensackkuppe ansgeschält und nun erst das Ligamentum medial am Knochen und lateral am Lid zugleich mit den Thränenröhrchen durchschnitten. An dem auf der vorderen $W$ and bleibenden Theil wurde der Sack fest gefasst und leicht aus scinem Bett herausgehoben. Beim Herauspräpariren des. 
Beitrag zur patholog. Anatomie der Thränensackerkranlsungen. 25

Sackes etwa eingetretene Perforationen des Sackes, sei es, dass die Wand angeschnitten wurde, oder dass dieselbe in Folge der starken Brüchigkeit des Gewebes einriss, wurden gewöhnlich mit Klemmpincetten provisorisch geschlossen. Der Operationsverlauf wurde dadurch niemals beeinflusst. Zum Schluss wurde der Sack möglichst tief am knöchernen Canal abgeschnitten, dieser selbst mit dicker Sonde sondirt und die Schleimhaut mit den scharfen Löffel ausgekratzt. Die Wunde wurde dann stets in ganzer Ausdehung durch 3 oder 4 tiefgreifende Suturen geschlossen. Fast immer wurde ganz aseptisch operirt, so gut wie niemals kamen Desinficientien irgend welcher Art mit der Wunde in Berïhrung.

Aus der gegebenen Beschreibung geht hervor, dass die Schnittführung sich am meisten der von Alfred Graefe empfohlenen näherte. Schreiber (l. c.) berichtet über dieselbe genauer: „Der Schnitt ca. $2 \mathrm{~cm}$ lang, $4 \mathrm{~mm}$ vom inneren Angenwinkel, wird ziemlich vertical mit dem oberen Ende etwas nach vorn geneigt, vorsichtig nur durch die äussere Haut geführt". Es folgt dann zunächst das Herauspräpariren der vorderen Wand, dann das Ausschälen des Thränensackes aus seinem Bett von hinten her und Abschneiden desselben am knöchernen Canal. Bekanntlich unterscheidet sich hiervon sehr wesentlich die $\mathrm{Kuhnt}$ 'sche (1. c.) Schnitführung. Nach Anspannung der Haut nach dem Nasenrücken zu, trennt Kuhnt, den Daumennagel fest auf die Crista anterior setzend, hart am Nagel schneidend, die Integumente sogleich bis auf den Knochen. Das fibröse Lidband, welches ofter dem Messer ausweicht, wird mit der Scheere (lateral) durchtrennt. Sodann wird die Capsula sacci längs der Crista incidirt. Es erfolgt dann die stumpfe Loslösung des Sackes vom Periost, zuletzt Ablösung desselben vorn und temporal und Abschneiden am knöchernen Caral.

Es wurde dieses Verfabren auch bei einer Reihe von 
E. Hertel.

unseren Fällen angewendet, doch entschloss sich Herr Prof. Wagenmann aufGrund der dabei gemachten Erfahrungen, der soeben genauer geschilderten Operationsmethode den Vorzug zu geben. Denn bei der seitlichen Schnittführung, wie sie Kuhnt angiebt, sind stärkere Blutungen gleich zu Beginn der Operation unvermeidlich. Dieselben erschweren das Freipräpariren des Sackes ausserordentlich. Bei der mehr lateral gelegenen Schnittführung, wie sie in unseren Fällen meist ausgefubrt wurde, kann man, was schon Schreiber betont, die vordere Wand des Sackes leicht frei legen, ohne grössere Grefässe - Zweige der Angularis oder Anastomosen der Frontalis - anzuschneiden. Ferner ist selbst bei der grössten Sorgfalt bei dem Einschneiden der Thränensacklaapsel an der Crista nach Kuhnt's Verfahren eine Mitverletzung der Wand leicht möglich, ein Punkt, auf den er selbst in seiner Beschreibung aufmerksam macht. Bei der mehr lateralen Schnittführung dagegen kommt man direct auf die vordere $W$ and und kann von hier aus leicht das weitere Herauspräpariren vornehmen. Dabei erleichtert das bis zuletzt straff gespannte Ligamentun internum ausserordentlich die Orientirung, namentlich auf der lateralen Seite nach dem Tid zu.

Einen Nachtheil, den Völckers(5) bei der Graefeschen Schnittführung beobachtete, dass nämlich die Narbe zur Ausbildung eines Ectropiums führte, konnte ich in den Fällen aus der hiesigen Klinik niemals sehen. Im Gegentheil die Narbe war fast überall schön linear, und in den meisten Fällen nach einiger Zeit fast gar nicht mehr zu sehen.

Das Einlegen "einer Wieke zwecks Drainage", wie es Kuhnt(l. c.) empfiehit, erwies sich niemals als nothwendig; eher möchte ich glauben, dass der primäre Wundschluss durch die Wieke, die doch immer zu Granulationen Anlass geben muss, verzögert werden kann. 
Beitrag zur patholog. Anatomie der Thränensackerkrankungen. 27

Ebenso wurde die Wunde niemals mit Desinficientien ausgespült, wie es Schreiber(1. s.), Völckers(l. c.) u. a. angeben. Selbst in den wenigen Fällen, in denen aus den durchtrennten Thränenröhrchen oder aus den in seltenen Fällen namentlich bei sehr starker Wandverdünnung kaum vermeidbaren kleinen Perforationsstellen etwas Secret in die Wunde geflossen war, beschränkten wir uns darauf, das Secret sorgfältig trocken aufzutupfen. Ausspülungen wurden auch hier nur ganz selten vorgenommen, um nicht den primären Wundschluss zu beeinflussen.

Wichtig ist zum Zustandekommen desselben die Anlegung des Verbandes. Es ist nöthig, um die Bildung eines Hohlraumes an Stelle des exstirpirten Sackes zu vermeiden, der die Veranlassung zu einer Anhäufung von Wundsecret oder von Blut werden könnte, die über der Wunde vernähte Haut fest an den Knochen anzupressen. Durch schmale, aber dicke Compressen, über welche die Binde recht fest angezogen wird, kann man das leicht erreichen. Der Verband bleibt zwei Tage liegen; er wird meist ganz gut vertragen. Das hier und da durch den starken Druck auftretende Lidödem und die allerdings noch seltener rorkommende geringe Chemosis sind ohne Bedeutung. Beides verschwindet nach Weglassen des Verbandes.

Am dritten spätestens am fünften Tage wurden die Suturen entfernt. Die Heilung war meist am siebenten Tage vollendet, $a b$ und zu war die Vernarbung allerdings erst am achten oder zehnten Tage eine vollständige. Secretverhaltung mit nachfolgender Vereiterung von Suturen wurde nur zweimal beobachtet. Doch legten sich auch hier die Wundränder nach Entfernung der Suturen gut aneinander, und die Patienten konnten nach ca. 14 bis 16 Tagen entlassen werden.

Meist bestand nach der Heilung Thränenträufeln, welches aber in kurzer Zeit sichtlich abnahm. Patienten, welche sich längere Frist - 1/2 bis $1 \mathrm{Jahr}$ - nach der 
E. Hertel.

Operation wieder vorstellten, führten keinerlei Klage über Epiphora.

Die sehr oft neben dem Thränensackleiden bestehenden einseitigen Bindehautaffectionen wurden durch die Thränensackexstirpation günstig beeinflusst. Namentlich trat das bei neun Fällen hervor, in denen stärkere Schleimbautveränderungen - Röthung und Schwellung derselben von granulirendem Charakter - mit ausgesprochener, schleimigeitriger Secretion beobachtet wurden. Sehr bald nach der Exstirpation der Thränensäcke bot die Bindehaut wieder normales Ausseher.

Ich gehe nun noch kurz auf die Fälle von tuberculöser Thränensackerkrankung ein. Drei von den in biesiger Klinik hierher gehörigen Beobachtungen sind in einer kürzlich erschienenen Dissertation von K. Grobe(7) genauer beschrieben, und zwar bei zwei Kindern, von denen das eine einseitige, das andere doppelseitige echte Thränensacktuberculose aufwies. Zu diesen kam neuerdings ein vierter Fall hinzu. Bei allen drei Patienten lagen sichere Zeichen von tuberculöser Allgemeinerkrankung vor. Das Krankheitsbild des Thränenleidens unterschied sich wesentich won dem der bisher besprochenen Fälle. Aus der tumorartigen Prominenz in der Thränensackgegend liess sich durch Druck wenig oder gar kein Secret entleeren. Die Haut über der ziemlich fest anzufühlenden Geschwulst war leicht livid verfärbt und liess eine Fistelöffnung erkennen, deren Ränder durch Granulationsgewebe verdickt war; nur in dem von Grobe beschriebenen Fall von doppelseitiger Erkrankung des Thränensackes war es auf der einen Seite nicht zur Fistelbildung gekommen. Nach Anlegung des Hautschnittes sah man, dass der ganze Tumor ans speckigem Granulationsgewebe bestand, in welchem man den Thränensack kaum als solchen noch erkennen konnte. In zwei Fällen zeigte sich ausserdem eine tuber- 
Beitrag zur patholog. Anatomie der Thränensackerkrankungen. 29 culöse Erkrankung der knöchernen Nasenwand mit Sequester'bildung.

Bei diesen ausgedehnten Veränderungen war eine $\mathrm{Ex}$ stirpation in der geschilderten Weise nicht mehr ausführbar. Man beschränkte sich darauf, das Granulationsgewebe möglichst rein zu entfernen, zumeist mit dem scharfen Löffel; die nekrotischen Parthieen der Knochenwand wurden mit Hammer und Meissel weggenommen, der knöcherne Thränencanal sorgfältigst ausgekratzt, um eine möglichst weite Communication mit der Nase zu erzielen.

Nach Tamponade der ganzen Wunde mit Jodoformgaze wurde der Verband angelegt. Die Heilung beanspruchte in allen diesen Füllen eine viel längere Zeit, da man abwarten musste, bis durch gute Granulationen von der Tiefe her die Wunde sich geschlossen hatte.

Es wurde das schliesslich in allen Fällen erreicht, die Narbe war deutlicher zu sehen als in den anderen Fällen, doch war sie auch hier völlig fest und nichts mehr von dem prominenten Tumor oder einer Fistel vorhanden.

Schliesslich möchte ich noch erwähnen, dass ausser diesen drei Fällen, in denen die Tuberculose den Thränensack sicher ergriffen hatte, noch zweimal bei tuberculösen Individuen Thränensackerkrankungen beobachtet wurden, welche aber ganz unter dem Bild der chronischen Thränensackeiterung mit Ektasie des Sackes verliefen.

Grobe (l. c.) hat auch von diesen beiden Fällen den einen genauer beschrieben. Bei ihm, wie bei dem neuerdings hinzugekommenen, handelte es sich um Patienten mit ausgedehntem Lupus des Gesichtes. Die Thränensäcke waren in beiden Fällen sehr ektatisch, auf Druck entleerte sich eine reichliche Menge Eiter aus denselben.

Die Exstirpation konnte genau nach der angegebenen Methode ausgeführt werden. Die Heilung verlief per primam. Tch werde auf diese Fälle noch genauer bei der Mittheilung der anatomischen Veränderungen eingehen. 
Pathologisch-anatomische Befunde.

Das ganze durch die Exstirpationen gewonnene $\mathrm{Ma}$ terial wurde anatomisch untersucht. Durch Anlegung von Serienschnitten längs und quer durch die exstirpirten Thränensäcke versuchte ich mir ein anschauliches Bild von den pathologischen Vorgängen zu verschaffen. Auch die Thränencanälchen habe ich in einer grösseren Anzahl von Fällen anatomisch untersucht.

Makroskopisch sah ich zunächst in der Mehrzahl der exstirpirten Säcke, bei denen ja schon klinisch aus der vorhandenen reichlichen, eitrigen Secretion auf einen zur Zeit noch floriden, eitrigen Process geschlossen werden konnte, deutlich verdickte $W$ andungen, welche in flacheren oder stärker ausgebildeten Zotten in das Lumen lineinragten und dasselbe theilweis verlegten. Das Lumen selbst war in fast allen diesen Fällen deutlich erweitert, manchmal war die Ektasie eine ganz beträchtliche; ich fand Durchmesser von 4:10 mm (conf. Taf. I, Fig. 1) wobei zu berücksichtigen ist, dass die Präparate gehärtet gemessen wurden.

Nur an manchen Stellen - namentlich an der Einmündung der Thränencanälchen - war eine deutliche Verengerung des Lumens schon makroskopisch zu constatiren. Zweimal war der Sack in seinem unteren Theil fast ganz ohne Lumen, der obere dagegen beträchtlich ektasirt.

In den wenigen Fällen dagegen, in denen neben der reichlichen, aber dünnflüssigen Secretion die Ektasie schon klinisch ganz besonders in den Vordergrund trat, gleichsam als cystische Erweiterung der Säcke imponirend, war die Wandung stark verdünnt, mit divertikelartigen Ausstiilpungen versehen, die sich als lange Fortsätze weit in das umgebende Gewebe verfolgen liessen.

Zur mikroskopischen Untersuchung eigneten sich vor Allem diejenigen Thränensäcke, bei denen die Verände- 
Beitrag zur patholog. Anatomie der Thränensackerkrankungen. 31

rungen weder durch Sondencuren noch durch sonstige therapeutische Maassnahmen beeinflusst waren. Ich werde daher zunächst bei der Beschreibung nur Befunde zu Grunde legen, die ich bei nicht behandelten Thränensackerkrankungen erheben konnte, erst in zweiter Linie werde ich auf Präparate eingehen, die von sicher wegen ihres Thränenleidens behandelten Patienten stammen.

Zuerst bespreche ich die Veränderungen bei der chronischen Thränensackeiterung mit mehr oder weniger ausgesprochener Ektasie des Sackes (cf. Taf. I, Fig. 1 u. 2).

Mit schwacher Vergrösserung schon konnte man erkennen, dass die verdickten Wandungen ausser den schon erwähnten grösseren Zotten noch zahlreiche kleinere Fortsätze in das Lumen schickten. Diesen entsprachen oft Einsenkungen in die Mucosa, welche hier und da als rinnenartige Gänge imponirten, so dass also die ganze, dem Lumen zugekehrte Wandfläche ausserordentlich unregelmässig gestaltet war. Das Epithel folgte meist diesen Unebenheiten und fehlte nur selten auf kurze Strecken. $\mathrm{Ab}$ und $\mathrm{zu}$ fand man eine derartige Epitheleinsenkung ohne jeglichen Zusammenhang mit dem übrigen Epithel der Oberfläche: man sah mitten in der Mucosa liegend ein rundliches oder längliches Gebilde mit engem Lumen, das ausgekleidet war von Epithelzellen (cf. Taf. I, Fig. 2 u. Taf. II, Fig. 4). Bei der Durchsicht der Nachbarserien liess sich stets der Faltencharakter dieser Gebilde nachweisen.

Das Epithel selbst zeigte in der Mehrzahl der Fälle eine ausgesprochene Verbreiterung, welche meist auf eine Vermehrung der Zelllagen beruhte. 10 bis 15 und noch mehr Reihen konnte ich an manchen Stellen unterscheiden. Die Zellen an sich waren allerdings in diesen gewucherten Parthieen nicht so hohe Cylinderzellen, wie wir sie normaler Weise finden, sie waren mehr polymorph: nach dem Lumen zu schlanker und höher, die tieferen 
Schichten mehr von cubischer Gestalt. Die Kerne waren alle länglich, senkrecht zum Lumen gestellt. Oefter wurden diese compacten Schichten ron Epithelzellen ron eigenthümlichen, rundlichen Gebilden unterbrochen, die in rerschiedenster Grösse mit Haematoxylin leicht mattblau gefärht als homogene Kugeln erschienen. Meist waren sie von Epithelzellen vollkommen umgeben, öfter grenzten sie aber auch an die Oberfläche, nur seitlich von dem gewucherten Epithel flankirt.

An zahlreichen anderen Stellen sah man ferner die Verbreiterung des Epithels nicht durch die Vermehrung der Zelllagen, sondern durch die Umwandlung der einzelnen Zellen selbst hervorgerufen werden. Besonders war hier die innerste Lage verändert. Die Zellen waren entschieden vergrössert, sowohl verlängert, als auch verbreitert. Es waren im Ganzen sehr hohe cylindrische Gebilde, welche aber oft seitliche Anschwellungen erkennen liessen. Die dem Lumen zugekehrte Fläche war nicht selten aufgefasert - doch liessen sich weder hier noch sonst an einem Präparut deutliche Flimmerhaare nachweisen. Der Zellinhalt war fein granulirt von sehwacher Färbbarkeit. Der Zellkern, meist nahe der zweiten äusseren Schicht sitzend, war längsoval, hier und da etwas zerklüftet und ebenfalls schlechter tingirbar als gewöhnlich. Die zweite äussere Lage zeigte an diesen Stellen entweder keine oder nur geringe Veränderungen. Die Zellen waren gut gefärbt, viel niedriger mit länglichen Kernen; nur $a b$ und zu erschienen auch diese Zellen länger als normal und mehr von spindeliger Form.

Eingestülpte Falten der Oberfläche der Schleimhaut, welche die zuletzt beschriebenen Veränderungen des Epithels erkennen liessen, gewannen sehr leicht das Aussehen von drisigen Organen, besonders, wenn man sie in Schnit. ten zu sehen bekam, in denen die Finsenkung ohne Zusammenhang mit der Oberfäche rings von der Mucosa 
Beitrag zur patholog. Anatomie der Thränensackerkrankungen. 33

ungeben war. Die hohen, umgewandelten Zellen glichen ganz den Epithelzellen von Schleimdrüsen und doch handelte es sich mit Sicherheit nur um Einsenkungen von Epithelzapfen in die Mucosa (conf. Taf. II, Fig. 4).

Auffallend war der ausserordentlich grosse Reichthum von Becherzellen in fast allen untersuchten Präparaten. Diese durch ihre Grösse und Tinction sofort auffallenden Gebilde zeigten eine bauchige Gestalt, welche nach der tieferen Epithellage zu meist spitzer auslief. Die Kerne waren in dem tieferen Theil zu sehen nahe dem Beginn der Verjüngung. Meist waren die Zellen prall gefüllt mit bald mehr klarem, bald mehr gekörntem Inhalt. Dazwischen lagen schmälere, scheinbar entleerte Becherzellen. Selten standen sie vereinzelt, meist in kleinen Gruppen, öfter aber auch auf grösseren Strecken die Epithelauskleidung dor Wandung ausmachend.

Ferner fand sich durchweg eine Rundzelleninfiltration. des Epithels. Bald lagen die Leukocyten mehr diffus zwischen den Epithelzellen, bald mehr in deutlichen Haufen, hier und da so dicht, dass jede Epithelstructur verdeckt war und die infiltrirte Mucosa bis an die Oberfäche zu reichen schien. Sicher liess sich das constatiren an stricturirten Stellen. Hier lag Mucosa an Mucosa, man sah nichts mehr von einem Lumen, jedes trennende Epithel war verschwunden. Sonst aber liess sich ein Untergang des Epithels auf grössere Strecken niemals constatiren.

Dagegen war die Basalmembran, die normaler Weise das Epithel von der Mucosa trennt, fast niemals mit Sicherheit nachzuweisen. Das veränderte Epithel sass locker dem Gewebe darunter auf.

Die Veränderungen der Mucosa bestanden in einer meist sehr starken Hyperaemie mit theilweiser Neubildung von Gefässen und in einer ausgesprochenen Rundzelleninfiltration. 
Die zahlreichen Venen, die normaler Weise die Thränensackwand umspinnen und sie bis zu dem Epithel. durchsetzen, waren ganz prall gefüllt, das Lumen entschieden erweitert. Als breite, rothe Bänder erschienen sie in der Submucosa und dem angrenzenden Muskelgewebe der Umgebung. Zartere, theilweise sicher neugebildete Schlingen durchzogen die Mucosa selbst bis an das Epithel heran und führten hier zuweilen zu kleinen Gefässelstasieen. Sehr selten beobachtete ich Blutaustritte und dadurch bedingte Abhebung des Epithels.

Die Infiltration mit Rundzellen war ausserordentlich stark, sie verdeckte streckenweise vollkommen das lockere Gefüge der Mucosa und Submucosa. An manchen Präparaten war auch die dem Thränensack aufliegende Musculatur infiltrirt.

Von ganz besonderem Interesse waren schon bei gewöhnlicher Kernfärbung durch ihren dunkleren Farbenton auffallende Knötchen, die ganz gut makroskopisch wahrnehmbar waren; zuweilen erreichten sie Stecknadelkopfgrösse. Es waren diese derm Aussehen nach sofort an Follikel erinnernden Gebilde in fast allen untersuchten Thränensäcken zu finden, allerdings in wechseinder Grösse und Zahl. An Längsschnitten (conf. Taf. I, Fig. 2) konnte ich mich mit Sicherheit überzeugen, dass diese Follikel im ganzen Verlauf des Thränensackes sich fanden, in der Kuppe schienen sie mir verhältnissmässig spärlich zu seỉ, während sie im unteren Theil oft sehr massenhaft vorhanden waren. So zählte ich in einem. Querschnitt aus dem unteren Theil eines Thränensackes 16 Follikel.

In der Mehrzahl der Fälle fand ich sie in der Mucosa ziemlich dicht unter dem Epithel, seltener in den tiefsten Schichten der Mucosa und dem Muskelgewebe (conf. Taf. I, Fig. 1, 2, Taf. II, Fig. 6, 7). Oft sah ich Bilder, in denen die Knötchen direct von dem Epithel überlagert wurden, dasselbe vor sich her treibend; in anderen Fällen war das 
Beitrag zur patholog. Anatomie der Thränensackerkrankungen. 35

Epithel über dem Knoten stark verdünnt, in noch anderen fehtte es ganz über demselben, so dass er frei in das Lumen des Sackes ragte.

An wohl ausgebildeten Follikeln konnte man fast immer eine etwas. dunkler tingirte, die peripheren Schichten umfassende Zone von einem etwas helleren Centrum unterscheiden; hier und da traten auch nur kleinere und grössere hellere Fleckchen auf (Fig. 1). Die Zellen der peripheren Parthieen liessen eine annähernd concentrische Anordnung erkennen. Sie bestanden der Hauptsache nach aus ziemlich kleinen lymphoiden Zellen mit stark färbbarem Kern. $\mathrm{Ab}$ und zu sah man aber auch Stellen, wo die Tinctionsfähigkeit dieser Kerne sehr abgenommen hatte, sie erschienen unregelmässig contourirt, zerklïftet, in Zerfall begriffen.

Die im Centrum gelegenen Zellen waren entschieden grösser als die peripheren, oft von epitbeloidem Charakter mit grossem, blasigen Kern, der oft Kerntheilungsfiguren erkennen liess. Fast stets fand man in den Follikeln zahlreiche Gefässe, meist prall gefüllt mit deutlichem Uebergang in die reichlichen Gefässschlingen in der Umgebung. Oft gelang es mir, namentlich mit der Ehrlich'schen Triacidfärbung ein bindegewebiges Stroma der Follikel zu erkennen, in der Peripherie meist mit concentrischer Anordnung der einzelnen Bindegewebszïge. Es waren dann diese Follikel ganz besonders scharf von ihrer Umgebung abgesetzt. In den Knoten, in denen diese Abgrenzung weniger ausgesprochen war, verlief das Bindegewebe mehr in der Richtung des sonst in der Umgebung vorhandenen - also mehr längs oder quer. An derartigen Präparaten waren dann auch die lymphoiden Zellen nicht so concentrisch angeordnet, wie bei den scharf begrenzten Follikeln, vielmehr konnte man an Serienschnitten ganz deutlich erkennen, wie hier und da breitere oder schmälere Züge von diesen Lymphzellen gewissermaassen den Bindegewebszïgen folgend, sich in die Umgebung, die ihrerseits ja auch reich 
E. Hertel.

an Lymphzellen war, verliefen. Oefter stellten sich die Follikel nur als kleine verschwommene Fleckchen dar - Anhäufungen von lymphoiden Zellen mit ganz spärlichem Bindegewebe, ohne Grenzen allmählich in das umgebende lymphzellenreiche Gewebe übergehend.

Manchmal konnte man von einem an das Lumen grenzenden Knoten aus ganz deutlich eine Strasse von Lymphzellen in das Lumen des Sackes hinein rerfolgen, die sich hier mit dem übrigen Inhalt mischten. An anderen Stellen sah ich diese Lymphzellenzigge von länglichen, platten Gebilden ausgehen, die sich ihrerseits durch ihre lebhafte Tinction, ihre Zellformation und ihr bindegewebiges Stroma auch als Follikel documentirten. Doch waren diese geplatzt und hatten ihren Inhalt zum Theil entleert. Selten liess sich eine ausgedehntere Nekrose der Follikel nachweisen, nur an besonders grossen Knoten sah man kleinere Heerde, in denen ein devtlicher Zerfall der Zellelemente zu Tage trat.

Der in einer Anzahl von Präparaten im Lumen der Thränensäcke noch vorhandene Inhalt bestand der Hauptsache nach aus Eiterkörperchen und aus zerfallenen und veränderten Zellen der Wandungen. Namentlich konnte man zerfallene Epithelzellen zum Theil in schleimiger Degeneration begriffen wahrnehmen. Auch losgelöste Becherzellen - fanden sich. Seltener waren grössere Epithelschollen zu finden. An manchen Stellen überwogen bei weitem die einkernigen lymphoiden Zellen, welche nach gegebener Beschreibung aus den geplatzten Follikeln in das Lumen gelangt waren.

Wesentlich anders als die bisher beschriebenen Veränderungen bei der chronischen Eiterung der Thränensäcke gestalteten sich die Befunde bei jenen hochgradig ektatischen Säcken, welche makroskopisch schon eine beträchtliche Verdünung der Wandungen erkennen liessen.

Vor Allem fehlten hier so gut wie vollständig die entzindlichen Erscheinungen. Die Mucosa bestand aus 
Beitrag zur patholog. Anatomie der Thränensackerkrankungen. 37

strafferem, faserigen Bindegewebe mit spärlichen Kernen. Nur hier und da fanden sich einige ein- oder mehrkernige Rundzellen. Die beschriebenen eigenthümlichen Follikel fehlten in fast allen Präparaten. Die Gefässe waren spärlich, öfter erschienen ihre Wandungen etwas verdickt. Ebenso war die Muskellage der Wandungen entschieden reducirt.

Das Epithel, im Ganzen entschieden verschmälert, zeigte ausgesprochene Neigung zu Abplattung seiner Zellen. Die innere Schicht besonders war fast durchgängig von platten, verbreiterten Zellen gebildet, die äussere meist von ausgesprochen cubischen bis rundlich-ovalen Zellformen. Bei den am stärksten ektatischen Stellen hatte das Epithel ganz den Charakter von Plattenepithel, welches zum Theil eine starke Auseinanderziehung der einzelnen Elemente erkennen liess und streckenweise nur als einfache Lage plattcubischer Zellen die Mucosa deckte. Becherzellen oder an diese erinnernde Gebilde konnten in diesen Säcken fast niemals gefunden werden, ebenso fehlte die Rundzelleninfiltration des Epithels vollkommen (conf. Taf. II, Fig. 5).

Der Inhalt des Sackes bestand in einer mehr homogenen Masse mit bröckeligen Einschlüssen, in denen sich nur undeutlich zellige Elemente erkennen liessen.

Whe ich auf die aus der Beschreibung ja deutlich hervorgehenden Unterschiede zwischen den Präparaten bei der chronischen Eiterung der Thränensäcke und denen bei hochgradiger Ektasie derselben ohne entzündliche Erscheinungen eingehe, möchte ich erst die anatomischen Befunde besprechen, welche ich bei katarrhalisch afficirten Thränensäcken erheben konnte.

Das dazu nöthige Material gewann ich nach langem Suchen von zwei Patienten, welche an intercurrenten Krankheiten gestorben waren. Bieide standen in den zwanziger Jahren und litten schon seit geraumer Zeit an stärkerem Thränenträufeln, ohne dass irgend eine Behandlung eingeleitet worden war. Man konnte ans dem Thränensack in 
beiden Fällen $a b$ und zu eine Wenigkeit von ziemlich klarem Inhalt ausdrücken; die Schleimhaut der Lider und Uebergangsfalten war normal.

Wenige Stunden post mortem exstirpirte ich die Thränensäcke. An den in Serienschnitte zerlegten Präparaten fand sich Folgendes:

Das Lumen der Säcke war nicht sehr erweitert, aber durch zahlreiche kleinere und grössere Buchten unregelmässig, auch längere Seitengänge liessen sich mit Sicherheit nachweisen.

Das Epithel zeigte stellenweise ganz ähnliche Wucherungsvorgänge, wie wir sie bei den eitrigen Erkrankungen geschildert haben. Doch waren die Veränderungen lange nicht so hochgradig. Die Deformation der inneren Zelllagen, die Rundzelleninfiltration zwischen den Epithelzellen waren im Ganzen spärlich, wenn auch hier und da ganz deutlich. Auch liess sich ein so grosser Reichthum an Becherzellen, wie wir ihn bei Präparaten von der chronischen Thränensackblennorrhoe sahen, nicht nachweisen.

Die Mucosa war durch eine stärker lichtbrechende Basalmembran von dem Epithel fast überall gut getrennt. In der Mucosa, deren lockeres, bindegewebiges Gefüge man noch gut erkennen konnte, war eine deutliche diffuse Infiltration mit Rundzellen zu sehen. An manchen Stellen erreichte die Rundzelleninfiltration eine bedeutendere Dichtigkeit und erstreckte sich auch weiter in die Tiefe. An diesen Stellen war dann auch das Epithel von Rundzellen mehr durchsetzt, zum Theil sogar verdeckt.

Die Gefässe waren ausgedehnt und prall gefüllt, bis dicht unter das Epithel waren anch hier die Capillaren zu sehen.

In fast allen Schnitten, namentlich durch die unterhalb der Mündungsstelle der Thränenröhrchen gelegenen Sacktheile, fanden sich deutlich die besprochenen Follikel; in geringerer Zahl konnte ich dieselben auch im Fundus 
Beitrag zur patholog, Anatomie der Thränensackerkrankungen. 39

des Sackes nachweisen. Sie lagen in der Mucosa meist in geringer Entfernung rom Epithel, hier und da oberflächlicher vom Epithel entblösst, aber auch mehr in der Tiefe. Die Structur der einzelnen Knötchen unterschied sich nicht von der früher mitgetheilten: es waren scharf abgesetzte und weniger scharf begrenzte Follikel vorhanden, solche mit helleren Centren und mehr concentrischer Anordnung der Zellenelemente in der Peripherie. Ueberall fast liess sich ein die Knoten umspinnendes Gefäasnetz, von dem aus deutlich Gefïssschlingen in das Innere der Knoten gingen, nachweisen. Auch das bindegewebige Stroma zeigte dasselbe Verhalten wie bei den früher beschriebenen Follikeln.

Wir haben also bei diesen Präparaten eine sehr weitgehende Uebereinstimmung mit den bei der chronischen Eiterung erhobenen Befunden. Die Hyperämie, die Infiltration, die Deformation des Epithels, die Follikelbildung in der Mucosa waren bei beiden Gruppen vorhanden - nur bei der zuletzt beschriebenen alles in viel geringerem Grade. Während wir also klinisch beide Gruppen von Erkrankungen des Thränensackes sehr wohl trennen konnten und bei der zuerst geschilderten Gruppe die Diagnose auf eitrige Erkrankung des Sackes mit Elktasie stellten, bei der anderen dagegen nur von einer katarrhalischen Affection des Thränensackes sprachen - konnten wir anatomisch einen derartigen scharfen Unterschied nicht machen. Wir sahen nur graduelle Differenzen, dem Wesen nach waren die Veränderungen dieselben. Und es dürfte sehr schwer halten, nur aus den vorgelegten anatomischen Präparaten einen Rückschluss auf das klinische Bild der Erkrankung zu machen, ganz ähnlich, wie wir das ja von den Erkrankungen der Bindehaut auch wissen.

Auf die Aehnlichkeit der anatomischen Bilder bei dem chronischen Katarrh des Thränensackes und bei der chronischen Eiterung recurrirt auch Kuhnt(8), der ja in seinem 
bekannten Vortrag auf dem Heidelberger Congress 1891 an der Hand eines umfangreichen Untersuchungsmateriales die ersten genaueren Mittheilungen über die pathologisch anatomischen Veränderungen des Thränenschlauches brachte. Kuhnt (8) bespricht detaillirter die Befunde beim chronischen Katarrh, mit denen die meinigen der Hauptsache nach sebr gut iibereinstimmen, und sagt dann, dass bei eingetretener Blennorrhoe des Sackes die Infiltration und Schwellung der Schleimhaut noch viel beträchtlicher werde. Er weist sodann ganz kurz auf die hochgradigen Unebenheiten der Wandinnenfläche, auf die starke Hyperaemie und Gefässneubildung und auf die mannigfachen Veränderungen des Epithels hin, ohne auf die Details einzugehen, weil eben die ganzen Veränderungen nur Steigerungen von schon geschilderten waren. Ich kann das für meine Präparate, bei deren. Beschreibung ich gerade auf die Veränderungen bei der chronischen Eiterung genauer eingegangen bin, vollauf bestätigen.

Als die schliesslichen Folgen einer durch viele Jahre hindurch bestehenden, unbehandelten Thränensackeiterung stellt dann Kuhnt (l. c.) insbesondere eine Neoplasie der Schleimhaut mit nachfolgender Involution des Sackes hin. Er beschreibt Präparate, in denen die Schleimhaut stellenweis vollkommen atrophirt und durch "neugebildetes, wohl dem Narbengewebe gleichzustellendes Gewebe" ersetzt war. Das Epithel war der Hauptsache nach ein- oder mehrschichtiges Plattenepithel. Die partiellen Schleimhautatrophieen und Narbenbildungen haben dann nach seiner Ansicht $\mathrm{zu}$ Stricturen und $\mathrm{za}$ höchstgradiger Involution des Sackes geführt.

Anch ich habe Präparate beschrieben, die ähnliche Wandveränderungen aufwiesen: Atrophie und bindegewebige Degeneration der Mucosa, welche von einem Epithel mit sehr platten Zellen bedeckt war. Ich möchte diese Verannderungen ebenfalls als Ausgang der viele Jahre bestehen- 
Beitrag zux patholog. Anatomie der Thränensackerkrankungen. 41

den Thränensackerkrankung betrachten, welche zuerst zu der starken Infiltration, wie wir sie bei den eitrigen Processen sahen, und darn allmählich zur Bildung von Bindegewebe in der Mucosa gefuhrt hat. Doch scheint mir, dass in meinen Fällen noch etwas anderes als der in den Wandungen spielende Erankheitsprocess bei den hochgradigen Veränderungen mitwirkte. Ich beobachtete nämlich neben der fast vollkommen gleichmässigen Verdiunnung der Wand eine ganz beträchtliche Ektasie des Sackes, welche mir als alleinige Folge des Krankheitsprocesses der Wand nicht recht verständlich ist. Denn das Bindegewebe würde durch Schrumpfung doch wohl eher zu Stricturen und Involution des Sackes geführt haben, wie es ja auch von Kubnt (l. c.) beobachtet wurde. Dies scheint in meinen Präparaten, wie ich glaube, durch ein mechanisches Moment verhindert worden zu sein. Ich möchte annehmen, dass, wie so oft, bei Beginn des Thränenleidens eine Strictur im oder am Eingang des knöchernen Canals entstanden war. Im weiteren Verlauf gingen die Wandungen immer hochgradigere Veränderungen ein, die Secretion nahm mehr und mehr zu und führte erst zur mittleren und schliesslich zu der ausserordentlichen Ektasie, so dass also die Wandveränderungen einmal als Ausgang der entzïndlichen Processe, dann aber auch der mechanischen Dehnung durch das gestaute Secret zu betrachten sind. Die Gleichmässigkeit der Schleimhautatrophie, das Auseinanderweichen der Epithelzellen, die an den stärkst ektasirten Stellen am meisten abgeplattet waren, scheinen mir dafür zu sprechen. Man kann vielleicht diese ganzen Veränderungen am besten einer cystischen Degeneration des Thränensackes gleichsetzen.

Die auffallendsten Gebilde, die ausgenommen in den zuletzt besprochenen atrophischen Schleimbäuten der Ausgangsstadien von mir überall gefunden wurden, waren die Follikel, welche eine gesonderte Besprechung erfordern. 
Kuhnt(8) hat dieselben in seinem Vortrag in Heidelberg ebenfalls schon erwähnt; ex beschreibt sie als "follikelähnliche, von einem Gefässringe gewissermaassen umschlossene Gebilde, die lebhaft an Granula in der Conjunctiva erinnerten." In seiner im vorigen Jahre erschienenen Arbeit "Ueber die Therapie der Conjunctivitis granulosa" (4) giebt er eine genauere Beschreibung und Abbildung von Follikeln in der Thränensackschleimhaut eines Hingerichteten und spricht diese Gebilde als ,typische Granulosis" des Thränensackes an. Gleichzeitig führt er in dieser Arbeit drei andere auf Granulose der Thränenwege Bezug nehmende Autoren an: de Vincentiis, Cirincione und Kalt. Sonst finde ich diese Follikel noch erwähnt bei Vossius(9), welcher in seinem Lehrbuch schreibt, dass man bei Thränensackblennorrhoe bei gleichzeitig bestehendem Bindehauttrachom nauch in der Schleimhaut des Thränensackes ganz typische, follikelähnliche Gebilde eingelagert findet." Auch Haab(10) und Fick(11) welche Fälle von Thränensacktuberculose untersuchten, erwähnen die Follikel. Tch selbst habe sie ebenfalls - wie ich gleich hier vorausnehmen möchte, in Fällen von Tuberculose des Thränensackes gesehen.

Diese Regelmässigkeit der Wiederkehr dieser eigenthümlichen Gebilde bei so verschiedenartigen Krankheitsprocessen veranlasste mich zunächst dazu, Untersuchungen darüber anzustellen, ob etwa auch die normale Thränensackschleimbaut derartige Follikel enthielte oder nicht. In der Literatur konnte ich nur bei Walzberg(12) eine Erwähnung der Follikel in der normalen Thränensackschleimhaut finden. Stöhr (13) schreibt derselben zwar einen ausgesprochenen adenoiden Charakter zu, auch Sch walbe (14) erwähnt den reticulären Charakter der Mucosa, die individuell schwankende Lymphzelleninfiltration darbiete, aber eine Beschreibung von Follikeln geben sie beide nicht. Eben so wenig konnte ich eine solche in anderen anatomischen Lehrbüchern finden. Kuhnt(8) spricht bei seinen Angaben 
Beitrag zur patholog. Anatomie der Thränensackerkrankungen. 43

über die normale Sehleimhant auch nur von dem lockeren reticulären Gewebe derselben mit vielen, verschiedenartig tingirbaren Zellenlagerungen. Auch Michel(15) beschreibt lymphoide Zellen in der Schleimhaut, und Vossius (9) vergleicht sie mit adenoidem Gewebe.

Um mir durch eigene Anschauung eine Gewissheit uber diesen Punkt zu verschaffen, untersuchte ich eine Reihe von normalen Thränensäcken, und zwar aus den verschiedensten Lebensaltern.

Ich fand nun bei einem Fötus von 7 Monaten - das jüngste Stadium, welehes ich untersuchte - die Mucosa überall von einem schönen, zweischichtigen, hohen Cylinderepithel, an welchem ich eine Wimperung nicht wahrnehmen konnte, gedeekt. Sie bestand aus einem lockeren, bindegewebigem Stroma mit reichlichen Iymphoiden Zellen. Dieselben waren diffus in dem Stroma eingelagert - nur hier und da konnte ieh einen dichteren Conflux von diesen einkernigen Rundzellen constatiren, meist in der Nachbarschaft der Gefässe, welche auch in diesen Präparaten sehr zahlreich waren und ein weites Lumen erkennen liessen.

Bei Neugeborenen sodann, bei denen das Epithel des Thränensehlauches ganz normales Verhalten zeigte, fand sich die Mucosa ebenfalls von ausgesprochen leukocytärem Charakter. Auch hier waren Stellen zu sehen, in denen die Lymphzellen etwas dichter standen, ohne dass aber eine schärfere Sondernng dieser Anhäufungen vorhanden gewesen wäre.

Ieh untersuchte ferner noch Thränensäcke von Leuten im Alter von ca. zwanzig und ca. vierzig Jahren, bei denen ich intra vitam festgestellt hatte, dass eine Entzïndung des Thränensackes nicht bestand und aueh die Conjunetiven normal waren.

An den Schnitten dureh die Thränensäcke dieser Leute überzeugte ich mich ebenfalls von dem ganz normalen Verhalten des Epithels. Dasselbe war deutlich zweischichtig eylindrisch: die innere Schichte etwas höher, die änssere etwas niedriger. Flimmerhaare wurden auch hier nicht gesehen.

Die Mucosa zeigte bei den 20 jährigen Individuen gegenüber von Föten und Nengeborenen einen entschieden reichlicheren Gehait an Lymphzellen. Dieselben liessen sich als gleich- 
mässigere Infiltrationsschichte in dem Bindegewebsstroma unterseheiden. Die confluirenden Haufen wurden hänfiger, ab und zn auch waren dieselben etwas schärfer abgesetzt. Reichliche Gefässe mit grossem Lumen vervollständigten das Bild.

Bei den Individuen von ca, 40 Jahr war eine wesentliche Zunahme der diffusen Rundzelleninfiltration nicht zu bemerken, wohl aber fanden sich hiev grossere Stellen mit dichterer Rundzellenanhäufung, und auch deutlich abgesetzte, melr oder weniger rundliche Knoten. Auch hier waren die Gefässe weit und zahlreich. Die dichter infiltrirten Stellen und Knoten waren von Gefässen umsponnen, theilweise durchsetht (conf. raf. I, Fig. 3).

Aus diesen Präparaten geht also hervor, dass wir eine reichliche Vertheilung von Lymphzellen mit, Sicherheit normaler Weise in der Thränensackschleimhant haben. Dieselbe ist bei Föten and Neugeborenen im Wesentlichen diffus über die Mucosa rerbreitet, nur hier und da finden sich Stellen, welche eine bestehende Neigung zur Bildung von confluirenden Haufen anzudeuten scheinen.

Mit zunehmendem Alter lässt sich eine Vermehrung der diffusen Lymphzelleninfiltration constatiren and ebenso eine deutliche Ausbildung circumscripter Rundzellenanhäufungen, die schliesslich auch bei ganz normalem Epithel zur Follikelbildung im erörterten Sinne führen kaun.

Von den sicher erkrankten Thränensäcken zeigten die geringsten Veränderungen diejenigen, bei denen klinisch ein chronischer Katarrh durch eine geringe Menge klaren Secretes festgestellt war. Das Epithel war hier stellenweise deutlich verändert, die Rundzelleninfiltration viel stärker als in der Norm, stellenweise bis in das Epithel hinein. Die Follikelbildung hatte zugenommen. Bei den schwereren Processen, die mit deutlicher Eiterung einher gingen, war eine weitere Steigerung der Veränderungen zu beobachten. Das Epithel war durchweg hochgradig deformirt und infiltrirt. Die Knoten in der Mucosa zahlreich und oft, namentlich bei längerer Dauer des Processes, vollständig von ihrer Umgebung abgegrenzt. 
Beitrag zur patholog. Anatomie der Thränensackerkrankungen. 45

Auf Grund dieser Thatsachen scheint mir folgender Schluss berechtigt:

Die Schleimhaut des Thränensackes besteht aus einer von zweischichtigem, hohem Cylinderepithel gedeckten, lockeren, gefässreichen Mucosa, die normaler Weise reichlich mit lymphoiden Zellen infiltrirt ist, bei denen schon in der Anlage eine grosse Neigung zur Vermehrung und Bildung von mehr oder weniger abgeschlossenen Aggregaten bebesteht. Die Benetzung der Schleimhaut mit der Thränenflüssigkeit, die ja aus dem Conjunctivalsack, wie wir wissen, alle möglichen Beimischungen erhält, genügt, um den Reiz abzugeben für die Vermehrung der Lymphzellen und die Bildung von confluirenden Haufen in den mittleren Lebensjahren. Tch darf wohl darauf hinweisen, dass wir Aehnliches ja auch bei der Conjunctiva haben in den bekannten Follicularkatarrhen nach chemischen Reizen, vor Allem nach Atropin und Eserin. Bei allen krankhaften Affectionen des Thränensackes kommt es num aber zu ganz beträchtlich stärkeren Reizen. Schon beim einfachen Katarrh finden wir meist eine Stagnation der Thränenflüssigkeit in Folge Behinderung des Abflusses nach der Nase zu. Die stagnirende und von Mikroben meist wimmelnde Thränenflüssigkeit bewirkt die stärkere Reaction des Gewebes mit deutlich entzündlichen Erscheinungen, wie wir sie an den Präparaten sehen konnten: reichliche Rundzelleninfiltration, deutliche Vermehrung der Follikel, die zum Theil sich sehr scharf von der Umgebung absetzen, daneben Veränderungen des Epithels. Dickt sich dann das Secret mehr und mehr ein, so führen die damit verbundenen Zersetzungsvorgänge im Verein mit den stark vermehrten pathogenen Mikroorganismen zur eitrigen Entzündung mit den hochgradigen Veränderungen des Epithels und der Schleimhaut und mit ausgesprochener Follikelbildung, entsprechend der gegebenen Beschreibung.

Wie stark das eitrige Thränensacksecret an sich auf 
R. Hertel.

Schleimhäute einwirkt, geht aus der ja häufig zu beobachtenden gleichseitigen Conjunctivitis, die oft einen ausgesprochen granulirenden Charakter hat, hervor. Auch in unseren Fällen war neun Mal diese Complication vorhanden; nach Beseitigung der Thränensackeiterung heilte die Conjunctivitis zusehends fast ohne Anwendung einer localen Therapie.

Es kommen also die Follikel in der Thränensackschleimhaut auch unter physiologischen Verhältnissen vor. Ihre starke Vermehrung aber, verbunden mit überwiegend scharfer Abgrenzung gegen die Umgebung ist als ein Zeichen von Erkrankung des betreffenden Thränensackes anzusehen. Ich kann mich aber nicht dazu verstehen, wie Kuhnt (l. c.) in seinen Beobachtungen, in den Follikeln Trachomkörner zu sehen, die dem Bindehauttrachom gleichstehen. Die Beobachtung der Follikel in normalen Thränensäcken, ferner die regelmässige Wiederkehr derselben bei all' den zahlreichen pathologisch veränderten scheint mir dem zu widersprechen. Und das um so mehr, als gar nicht einzusehen wäre, warum in hiesiger Gegend, in welcher das Conjunctivaltrachom so selten ist, gerade das. Trachom des Thränenschlauches sich so häufig finden sollte, während $K u h n t(4)$ selbst schreibt, dass das letztere relativ viel seltener ist als das erstere.

Ich habe schliesslich auch eine grössere Anzahl von Nasenschleimhäuten nach Follikeln durchsucht. Für die Gewinnung des hierher gehörigen Materiales bin ich Herrn Dr. Löns, zur Zeit Assistenten an der Ohrenklinik, ausserordentlich dankbar.

Es kamen stets Stücke zur Untersuchung, welche möglichst aus der Umgebung der Einmündungsstelle des Thränennasencanales in den unteren Nasengang unter der unteren Muschel entnommen waren.

Ich will mich auf die gefundenen Details weiter nicht einlassen, da ja hier nur der Befund von Follikeln 
Beitrag zur patholog. Anatomie der Thränensackrerkrankungen. 47

interessirt. Ich untersuchte zunächst eine Anzahl von Nasenschleimhänten, die von Individuen stammten, welche Thränensackblennorrhoe hatten, und zwar mit und ohne complicirendes Bindehauttrachom. Bei beiden Gruppen fand ich keine ausgesprochenen Follikel in der Schleimhaut der Nase; unter dem manchmal deutlich flimmernden Cylinderepithel lag ein fibrilläres Bindegewebe mit wechselndem Reichthum an Leukocyten, welche aber nur sehr selten eine dichtere Anhäufung erkennen liessen.

Aehnlich war der Befund bei solchen Individuen, die Bindehauttrachom ohne Thränensackblennorrhoe hatten: bei ihnen, wie auch bei Leuten mit normalen Conjunctiven konnte ich nichts von trachomähnlicbem entdecken.

Nur in einem Falle war die Bildung von confluirenden Lymphzellenhaufen etwas ausgesprochener - es handelte sich hier aber um einen Fall von Empyem der Nasennebenhöhlen, welches lange Zeit bestanden hatte und zu eitriger Secretion in die Nase geführt hatte. Die Schleimhaut der Lider und der Thränensack waren normal. Parthieen von Nasenschleimhaut aus der Eiterstrasse entnommen liessen eine etwas deutlichere Rundzellenanhäufung erkennen als die übrige Schleimhaut. Es scheint das also wiederum ein Analogiebeweis zu sein für meine Annahme, dass die Follikelbildung als eine Reaction anzusehen ist von lymphoiden Gewebe auf chronische Reize. Doch war auch in diesem Falle von einer Follikelbildung in der Nasenschleimhaut in den Sinne, wie wir sie beschrieben haben, nicht die Rede.

Ich glaube daher, dass die Frage des Nasentrachoms erst dann einen sicheren Boden gewinnen kann, wenn weitere umfassendere anatomische Untersuchungen in dieser Richtung angestellt sein werden.

Auch auf einen anderen, noch strittigen Punkt habe jch bei der Durchsicht meiner Präparate geachtet: nämlich 
darauf, $a b$ Drüsen in der Thränensackschleimhant vorkommen oder nicht.

Ohne des Näheren auf die daruber vorhandene Literatur einzugehen, möchte ich nur erwähnen, dass vor Allem R. Maier (16) und nach ihm Henle (17), Stellwag v. Carion (18), Brösicke(19), Fuchs(2), Kuhnt(8) u. a. mit Bestimmtheit das Vorhandensein von wirklichen Drüsen in ihren Beschreibungen der Thränensackschleimhaut notirt haben. Dass dagegen Panas (20), Robin und Cadiat(21), vor Allem auch Walzberg (l. c.) ihr Vorhandensein mit derselben Bestimmtheit in Abrede stellen.

Ich muss mich auf Grund der zahlreichen Präparate, die ich mit möglichster Sorgfalt gerade auch mit Rücksicht auf diese Frage durchgesehen habe, auf Seite der letzten Autoren stellen. Ich konnte weder an der normalen, noch an den pathologischen Thränensäcken echte Drïsen finden. Allerdings waren, namentlich an dem pathologisch veränderten Material oft in grösserer Anzahl Gebilde vorhanden, welche ganz das Aussehen von Drüsen boten. Es waren das aber die schon beschriebenen mit dem veränderten Epithel oder auch mit Becherzellen ausgekleideten Einstülpungen die auf Durchschnitten, namentlich wenn sie mehr in der Tiefe der umgebenden Mucosa lagen, wirklichen Drüsen - tubulöser Natur - sehr ähneln, wie auch schon Vossius (1. c) in seinem Lehrbuch erwähnt. In den normalen Präparaten fand ich derartige drüsenähnliche Epithelabschnürungen sehr viel seltener; es mag das daher kommen, weil die Falten- und Buchtenbildung hier längst nicht so ansgesprochen und tief ist, wenn auch die Einstiilpungen, selbst bei fötalen Präparaten nicht ıur mikroskopischer Natur waren, wie Kuhnt (8) es für die normalen Verhältnisse postulirt.

Ferner kam ich beziglich der Becherzellen auf Grund meiner Präparate zu der Anschauung, dass sich dieselben auch in den ganz normalen Thränensackwandungen finden, 
auch beim Fötus. Aehnliches hat bekanntlich L. Green (22) für die Conjunctiva nachgewiesen. Doch waren die Becherzellen in der normalen Thränensackschleimhaut sehr spärlich, ja in manchen Schnitten fehlten sie ganz. Es ist daher der überaus reiche Gehalt an Becherzellen in den Präparaten bei Thränensackeiterung eine durch den Krankheitsprocess bedingte pathologische Erscheinung. Man muss demnach, ähnlich wie Waldeyer (23) das für die Conjunctiva annimmt, der obersten Epithellage „die Neigung, sich in grosse schleimführende, becherähnliche Zellen umzuwandeln" zuschreiben. Die in meinen Präparaten gefundenen überaus hohen und gleichzeitig breiten Cylinderzellen mit ihrem hellen, zum Theil auch granulirten Inhalt und blasigen Kernen, welche hier und da leichte Ausbuchtungen des Zellleibes erkennen liessen, stellten wohl die Uebergangsformen zu den ausgesprochenen bauchigen Formen der Becherzellen dar. Bei längerer Dauer des Processes wandelten sich schliesslich immer mehr Cylinderzellen in Becherzellen um, so dass stellenweise überhaupt nur Becherzellen die Mucosa deckten. Aehnlich sah auch Reich(24) bei mehr oder weniger starken Affectionen der Bindehaut pathologischer Weise eine theilweise schleimige Metamorphose der Epithelzellen eintreten.

Einer besonderen Besprechung möchte ich nun kurz einen Fall unterziehen, bei dem sich ein Schleimphautpolyp im Thränensack fand. Derselbe gehörte einer jungen Frau an, die längere Zeit schon durch das Thränenleiden belästigt worden war. Klinisch bot sich das übliche Bild des ektatischen, prominirenden Thränensackes. Auf Druck entleerte sich nur wenig Secret, der Tumor blieb von ziemlich constanter Form, fühlte sich teigig an,

Es wurde nicht sondirt, sondern sofort die Exstirpation in der geschilderten Weise ausgeführt.

An dem Präparat zeigte sich zunächst eine deutliche Ektasie des Sackes mit unregelmässiger Buchtenbildung. 
Die Schleimhaut bot das Bild des chronischen Thränensackkatarrhs mit den beschriebenen Veränderungen des Epithels und der Mucosa. Besonders erwähnen möchte ich, dass hier einige sehr schöne, ganz tief in der Submucosa sitzende Follikel zu sehen waren.

Das Interessante an dem Fall war, dass von der medialen Wand ausgehend ein gestielter Tumor in das Lumen hineinragte. Wie man an Serienschnitten deutlich sehen konnte, begann derselbe oben mit schmaler Basis, wurde nach unten zu immer breiter und fullte, kolbenartig gestaltet, schliesslich den grösseren Theil des Lumens aus (conf. Taf. II, Fig. 6 and 7). Man konnte deutlich den Ausgang dieses Tumors von der Mucosa feststellen. Man sah an der Tumorbasis, wie die bindegewebigen Faserziuge derselben mit der diffusen Rundzelleninfiltration und zahlreichen Gefässen sich direct in den eingeschnürten Hals fortsetzten, dann allmählich sich ausbreitend die ganze Tumormasse ausmachten. Das ganze war überzogen von theilweise gewuchertem, theilweise in schleimiger Degeneration begriffenem Epithel. Wir haben also eine ausgesprochene hyperplastische Wucherung der Schleimhaut, die sich weit über die Oberfläche erhebt and nur mit schmaler Basis der Unterlage aufsitzt: also einen echten Schleimhautpolypen, wie wir sie in der Nase, dem Uterus u. s. w. öfter beobachten, beim Thränensack aber nach Kuhnt's (1. c.) Mittheilung sehr selten zu sehen belrommen.

Ich gehe nun zu den anatomischen Befunden über, welche bei den Thränensackerkrankungen tuberculöser Individuen erboben werden konnten.

In den Fällen, in denen schon klinisch, wie ausgeführt, eine echte Tuberculose des Thränensackes angenommen werden musste, fanden sich in dem operativ entfernten Gewebe ausgesprochene tuberculöse Veränderungen sowohl in den beiden von Grobe (l. c.) schou mitgetheilten Fällen, 
Beitrag zur patholog. Anatomie der Thränensackerkrankungen. 51

als auch in dem erst neuerdings zur Beobachtung gekommenen Fall. Man sah in dem das Lumen und die Wandungen fast ganz durchsetzenden Granulationsgewebe zahlreiche kleine und grössere Tuberkelknoten mit ausgesprochenen epitheloidalen Zellen und zahlreichen, zum Theil recht grossen Riesenzellen. Auch in den noch erhaltenen Wandresten liessen sich neben den Zeichen der chronischen Thränensackeiterung tuberculöse Heerde mit Riesenzellen nachweisen.

Tuberkelbacillen wurden weder von Grobe noch von mir gefunden.

Trotzdem war aber die Diagnose auf Tuberculose des Thränensackes über jeden Zweifel erhaben, und zwar handelte es sich in allen drei Fällen um secundäre Tuberculose. Wie Grobe schon ausgeführt hat, ist die Möglichleit der Uebertragung bei solchen Individuen, die offene tuberculöse Heerde haben, dadurch gegeben, dass die Bacillen direct in den Bindehautsack rerschleppt werden und durch die Thränenflüssigkeit in den Thränensack gelangen, in dessen Buchten sie sich fest nisten und wuchern können. In anderen Fällen muss man an ein Uebergreifen des Processes. von tuberculös erkrankten Nachbartheilen denken z. B. von der Conjunctiva wie Haab (l. c.), Fick (l. c.), Gajet (25), Leidholt (26) beobachten konnten. Oft wird, wie auch in zwei von unseren Fällen, zweifellos die Erkrankung des Thränensackes herbeigeführt durch eine tuberculöse Periostitis der Nasenknochen, die ihrerseits entweder als Folge einer localen Nasentuberculose oder durch Verschleppung des Infectionsmaterials auf dem Blut- oder Lymphwege entstehen kann.

Diesen vier Fällen echter Thränensacktuberculose stellten wir schon im klinischen Theil zwei andere gegenüber. Es handelte sich bei diesen um Individuen mit ausgedehntem Lupus des Gesichtes, bei denen eine eitrige Thränensackerkrankung mit starker Ektasie des Sackes nachweis- 
bar war. Anatomisch fanden sich dem entsprechend im Wesentlichen die Veränderungen der chronischen Eitermg mit Sackektasie, wie sie ja eingehend beschrieben worden sind. Nur in den untersten Theilen der beiden Thränensäcke konnte man neben den gewöhnlichen Follikeln vereinzelte Knoten nachweisen, die als tuberculös verdächtig erscheinen konnten. Es fanden sich epitheloide Zellen und Andeutung von Riesenzellen. Man wird sich also in diesen beiden Fällen vorzustellen haben, dass in Folge der lupösen Nasenveränderungen eine chronische Thränensackblennorrhoe eingetreten ist. Vielleicht lässt die Andeutung tuberculöser Erkrankung im untersten. Theile des Sackes den Gedauken zu, dass der lupöse Process im Begriff war, direct auch auf den Thränensack selbst überzugreifen.

Wenn wir nun noch kurz auf die Thränenröhrchen eingehen, so kann ich zunächst die Angabe von Kubnt (8) bestätigen, dass man sowohl in den normalen, wie in den pathologischen Präparaten sehr deutlich das eigentliche Röhrchen von dem sogen. "Mündungsstück" in den Sack unterscheiden kann. Das eigentliche Röhrchen zeigte nur ganz ausnahmsweise geringe pathologische Veränderungen; meist sah man die zahlreichen Schichten des Plattenepithels, dessen äusserste Lage cylindrisch war, der bindegewebigen Tunica propria völlig normal aufsitzen. Die Tunica, wie in der Norm reich an elastischen Fasern, war aussen ron den wohl ausgebildeten, quergestreiften, circulären Muskelfasern umlagert. Nur selten komnte ich eine reichlichere Lymphzelleninfiltration in der Tunica propria constatiren.

Dagegen war das die Regel in dom sogen. Mündungsstück. Hier war das Epithel auch an meinen Präparaten ganz wie Kuhnt (l. c.) es beschreibt - in hohes Oylinderepithel übergegangen, unter dem eine lockere Mucosa sich befand, in normalen wie pathologischen Präparaten von deutlich lymphoidem Charakter. Eine ausgesprochene Follikelbildung sah ich bei den normalen Thränenröhrchen, wie auch bei 
Beitrag zur patholog. Anatomie der Thränensackerkrankungen. ōฐ den pathologisch veränderten nur im Mündungsstück, beí den pathologischen Präparaten ausgesprochener als bei ders normalen. Ausserdem zeigten die pathologischen Präparate eine starke Füllung der Gefässe, reichliche diffuse Infiltration mit Rundzellen in der Mucosa und deren Umgebung. Auch das Epithel war meist stärker mit Rundzellen durchsetzt, hier und da zeigte es ähnliche Veränderungen wie im Sack, nur selten fehlte es. Becherzellen waren vorhanden, aber nur sehr spärlich.

Hier und da waren die Röhrchen sehr ausgedehnt theils mit, theils ohne ausgesprochene Vexdünnung der Wandung. In einem Falle fand sich eine deutliche cystenartige Ausbuchtung fast des ganzen Röhrchens. Die Epithellagen waren hier reducirt, die Tunica ein straffes Bindegewebe, die normaler Weise sehr gut ausgebildete Musculatur deutlich atrophisch. Es gehörte dieses Röhrchen einem der ausserordentlich ektatischen Säcke an; wir sehen, dass sich auch in ihm atrophische und fibröse Degeneration der Schleimhaut geltend macht, welche wir bei dem Sack genauer besprochen haben.

Auch einen Fall von einer beginnenden Obliteration des Thränenröhrchens konnte ich beobachten. Die Präparate erinnerten sehr an die Beschreibung, die Bock (27) in seinem Atlas von einer bei Xerophthalmus beobachteten Obliteration giebt. Das Lumen war auch in meinem Falle durch bindegewebige Stränge, welche als Schiedwände der Länge nach das Röhrchen durchzogen, in mehrere Abtheilungen getheilt. An einer Stelle war das Lumen in der unteren Hälfte grösstentheils von neugebildetem Bindegewebe ausgefüllt, so dass nur in dem oberen - allerdings hier erweiterten Theil - ein Weg für die Thränenflüssigkeit blieb.

Ich habe nun zum Schluss noch über die Veränderungen zu berichten, welche ich an Thränensäcken erheben konnte, deren Erkrankung man vor der Exstirpation durch 
therapeutische Maassnahmen zu beeinflussen versucht hatte. Es handelte sich in Wesentichen um Sondencuren, welche mit oder ohne nachfolgende Durchspülung kürzere oder längere Zeit fortgesetzt waren.

Bei einer Reihe von Fällen, bei denen selbst mehrere Male vorsichtig sondirt worden war, sah ich so gut wie gar keinen Unterschied gegenüber den Bildern, die ich bei den nicht sondirten Fällen gefunden hatte.

Oft beschränkten sich sodann die Veränderungen auf nur ganz geringe Abschürfungen des Epithels in seiner ganzen Dicke, oder auch nur der oberflächlichen Schichten.

In der grösseren Anzahl von Fällen dagegen namentlich nach oft wiederholten Sondirungen mit Durchspülung mittelst der Hohlsonde - waren ausgesprochene Zertrümmerungen des Gewebes vorhanden. Auf grosse Strecken fehlte das Epithel, auch die Mucosa zeigte verschiedentlich lacerirte Stellen. Ausgedehnte Blutungen waren im Lumen und auch in der Schleimhaut zu constatiren. Hier und da war sogar eine losgetrennte Schleimhautzotte im Lumen zu sehen. Namentlich waren an verengten Stellen die Verletzungen des Gewebes recht hochgradige; ein Lumen allerdings liess sich immer constatiren (cf. Taf. I, Fig. 8).

Besonders erwähnen möchte ich noch einen Fall, den ich einem auswärtigen Collegen verdanke. Der Patient war viele Monate lang wegen chronischer Thränensackeiterung mit der Vulpius'schen Dauersonde behandelt worden. Die Schnitte, welche ich mir von dem Thränensack anfertigte, zeigten ein ganz anderes Bild als die bisher beschriebenen (conf. Taf. II, Fig. 9). Man sah einen schmalen, ziemlich geraden Spalt - das Lumen darstellend. Die Wandungen waren glatt, liessen nichts von den sonst ublichen Erhebungen oder Einschnürungen erkennen. Das Epithel fehlte fast durchweg, nur am unteren und oberen Fnde sah man $a b$ und zu eine kleine Epithelinsel. Die Wandungen liessen deutlich zwei Schichten erkennen. Die 
Beitrag zur patholog. Anatomie der Thränensackerkrankungen. 55

dem Lumen näher gelegene bestand aus ziemlich straffen. Zügen von Bindegewebe von sklerotischem Charakter, mit sehr spärlichen Kernen und wenigen, ebenfalls sklerotischen Gefässen. Die mehr periphere hatte mehr Schleimhautcharakter. Das Gewebe war lockerer, zeigte deutliche Lymphzelleninfiltration hier und da mit unvollständiger Follikelbildung; die Gefässe hatten auch hier anscheinend verdickte $W$ andungen, wie überhaupt nicht zu verkennen war, dass auch dieser Theil der Schleimhaut zur sklerotischen Atrophie neigte.

Nach all' dem ergiebt sich nach meiner Ansicht aus den von sondirten Thränensäcken gewonnenen Präparaten für die Frage der Therapie die ja allerdings schon längst bekannte Thatsache, dass forcirte Sondencuren entschieden zu verwerfen sind. Denn durch die ausgedehnten Läsionen des Gewebes, welche sie veranlassen, geben sie Anstoss $z u$ abnormen Verklebungen und Verwachsungen und an Stelle der gewaltsam durchtrennten Strictur entstehen andere. Andererseits ist aber nach den Präparaten wohl der Schluss berechtigt, dass vorsichtiges Sondiren, nicht zu oft wiederholt, nicht $\mathrm{zu}$ diesen Befürchtungen Anlass geben kann. Denn die kleinen Epithelläsionen, die oft auch hier unvermeidbar sind, werden bald regenerirt werden, wenn man nur dem Epithel Zeit dazu lässt. - Aus den Veränderungen, die wir nach langer Anwendung der Dauersonde in einem Falle eintreten sahen, scheint mir folgendes hervorzugehen: so lange die Sonden im Canal liegen, werden sie wohl denselben offen halten. Entfernt man sie aber nach einiger Zeit, so werden sich die durch den Reiz stark sklerotisch veränderten Wandungen mehr und mehr zusammenziehen, und das Lumen wird, da ja das Epithel fast ganz fehlt, schliesslich so gut wie ganz verschwinden können - also statt einer Offenhaltung des Canales hat man schliesslich eine Verödung desselben herbeigeführt. 


\section{Nachtrag.}

Nach Abserdung der vorliegenden Arbeit zum Druck fand ich den soeben erschienenen Aufsatz ron $K$. Jörss aus der Angenklinik zu Giessen „Beiträge zur normalen und pathologischen Histologie des Thränenschlauches" (Beiträge zur A ugenheilkunde, Heft XXXV). Es ist mir leider uumöglich, auf denselben noch genauer" einzugehen.

Erwähnen möchte ich nur, dass meine pathologischanatomischen Befunde bei der eitrigen Thränensackentzündung der Hauptsache nach mit den ron Jörss sehr gut übereinstimmen. Insbesondere spricht auch er die Ansicht aus, dass man die Follikel in der Thränensackwand nicht als Trachomfollikel ansehen kann, dass dieselben vielmehr eine regelmässige Erscheinung bei der Thränensackblennorrhoe sind. Ich bin, wie aus meinen Ausführungen hervorgeht, zu dem Resultat gekommen, dass die Follikel auch in der normalen Thränensackschleimhaut vorhanden sind und dass bei allen pathologischen Veränderungen derselben eine Vermehrung und schärfere Absetzung der Knoten von der Umgebung eintritt.

Von dem Vorhandensein von echten Drüsen in der Thränensackschleimhaut, wie sie Jörss beschreibt, konnte ich mich nicht iiberzengen.

Schliesslich möchte ich noch erwähnen, dass ich auch meine Präparate zum grössten Theil auf Mikroorganismen untersucht habe, dass ich aber wegen der grossen Inconstanz der Befunde absichtlich von einer Mittheilung derselben in der Arbeit verzichtet habe.

\section{Literaturverzeichniss.}

1) R. Schirmer, Erkrankungen der Thränenorgane. Handbuch v. Graefe-Saemisch. Bd. VII.

2) E. Fuchs, Lehrbuch der Augenheilkunde. 
Beitrag zur patholog. Anatomie der Thränensackerkrankungen. 57

3) P. Schreiber, Zur Thränensackexstirpation. v. Graefe's Arch. f. Ophthalm. XXVII. 2.

4) H. Kuhnt, Ueber die Therapie der Conjunctivitis granulosa. Klin. Jahrbuch. VI. 4.

5) W. Czermak, Die augenärztlichen Operationen. Wien 1893.

6) Völkers: citirt in der Dissertation von $J$. Ammon, Beitragzur Statistik der Thränensackexstirpation. Kiel 1892.

7) K. Grobe, Zur pathologischen Anatomie der Thränensacktuberculose. Dissertation. Jena 1898.

8) H. Kuhnt, Zur Pathologie und Therapie des thränenableitenden Apparates. Bericht der ophthalm. Gesellsch. Heidelberg. 1891.

9) A. Vossius, Lehrbuch der Augenheilkunde.

10) Haab, Die Tubereulose des Auges. v. Graefe's Arch. f. Ophthalm. Bd. XXY.

11) Fick, Tuberculose des Thränensackes. Correspondenzblatt $f$. Schweizer Aerzte.

12) Th. Walzberg, Veber den Bau der Thränenwege der Haussäugethiere und des Menschen. Rostock 1876.

13) Ph. Stöhr; Lehrbuch der Histologie. Jena 1894.

14) G. Schwalbe, Lehrbuch der Anatomie der Sinnesorgane. Erlangen 1887.

15) J. v. Miche1, Lehrbuch der Augenheilkunde.

16) R. Maier, Ueber den Bau der Thränenorgane, insbesondere der Thränen ableitenden Wege. Freiburg 1859.

17) Henle, Zur Anatomie der Thränenwege u. zur Physiologie der Thränenleitung. Zeitschrift f, ration. Medicin Bd. XXIII. 1865.

18) Stellwag v. Carion, Lehrbuch der Augenheilkunde. Wien 1870.

19) Brösicke, Normale Anatomie.

20) Prnas, Traité des maladies des yeux. 2. Vol. Editeur Masson.

21) Robin et Cadiat, Note sur la structure du suc lacrymal et de ses conduits. Robin. Joumal de l'anatomie 1875.

22) L. Green, Ueber die Bedeutung der Becherzellen der Conjunctiva. v. Graefe's Arch. f. Ophthalm. XL. 1.

23) Waldeyer, Handbuch d. ges. Augenheilkunde ron GraefeSaemisch. Bd. I.

24) Reich, M., Zur Histologie der Conjunctiva des Menschen. Mit 3 Tafeln. v. Graefe's Arch. f. Ophthalm. XXI. 1.

25) Gajet, Tuberculose primitive de la conjunctive propagée au sac lacrymal. (Soc franç. d'ophtalm. 1885.)

26) Leidholt, Beiträge zur Casuistik der Augentuberculose mit specieller Berücksichtigung der Tumorenform. Halle 1889.

27) Wedl a. Bock, Pathologische Anatomie des Auges. Wien 1886.

Erklärung der Abbildungen auf Taf. I-II, Fig. 1-9.

Fig. 1. Quersehnitt durch einen ektatischen Thränensack mit chronischer Blennorrhoe bei 15facher Vergrösserung.

$F=$ Follikel; $D=$ Drüsenähnliche Epithelabschnürungen.

$F_{1}=$ in Zerfall begriffene Follikel.

$J=$ Thränensackinhalt. 
38 E. Hertel, Beitrag z. pathol, Anatomie d. Thränensackerkrankungen.

Fig. 2. Längsschnitt durch einen ektatischen Thränensack mit chronischer Blennorrhae bei 14 facher Vergrösserung.

$F=$ Follikel $; \quad D=$ drüsenähnlicbe Epithelabschnürungen bei $D_{\mathbf{1}}$ mit grossen Becherzellen.

F i g. 3. Schnitt durch einen normalen Thränensack eines 40jährigen Mannes bei 15 facher Vergrösserung.

$I^{\top}=$ Follikel.

$F^{t}=$ mehr diffuse lymphoide Zellen.

$F_{\text {z }}=$ stärkere Anhäufung derselben.

Fig. 4. Schnitt durch infiltrirte Mucosa und verändertes tapithel bei chronischer Thränensackeiterung. (Zeiss, Object. E. Ocul. 2.)

$E=$ schleimig degenerirtes Epithel.

$B=$ Becherzellen.

$D=$ Drüsenähnliche Epithelabschnürung.

$S=$ infiltrirtes Schleimhautstroma.

Fig. 5. Schnitt durch die veränderte Schleimhaut eines Thränensackes bei höchstgradiger Elitasie desselben (cystische Degeneration). (Zeiss Object. E. Ocul. 2.)

$E=$ abgeplattetes Epithel.

$M=$ fibrös degenerirte Mucosa mit ganz spärlichen Lymphzellen.

Fig, 6-7. Querschnitte durch den Thränensack mit dem Schleimhautpulypen bei einer 5 fachen Vergrösserung, Fig. 6. Schnitt aus dem oberen, Fig. 7 aus dem untersten Theil des Sackes. $P_{1}=$ Polyp noch im Zusammenhang mit der Mucosa;

$P^{i}=$ frei in das Lumen ragender Theil des Polypen. $F=$ grosser, tief in der Musculatur sitzender Follikel.

F i g. 8. Längsschnitt durch einen Thränensack mit chronischer Blennorrhoe nach starken Sondirungen bei 10 facher Vergrösserung.

$E=$ erhaltenes Epithel im Fundus.

$G=$ zertrümmertes Gewebe frei im Lumen.

$S=$ Spalt in der Wandung, wohl traumatischen Ursprungs.

$H=$ Haemorrhagieen.

$F=$ Follikel.

Fig. 9. Sehnitt durch einen Thränensack, der mit Dauersonde behandelt wurde, bei 15facher Vergrösserung.

$T=$ sklerotischer TheiI der Schleimhaut.

$M=$ lockere Schleimhaut mit Lymphzelleninfiltration.

$G=$ sklerotische Gefässe.

$E=$ Epithelreste. 
证
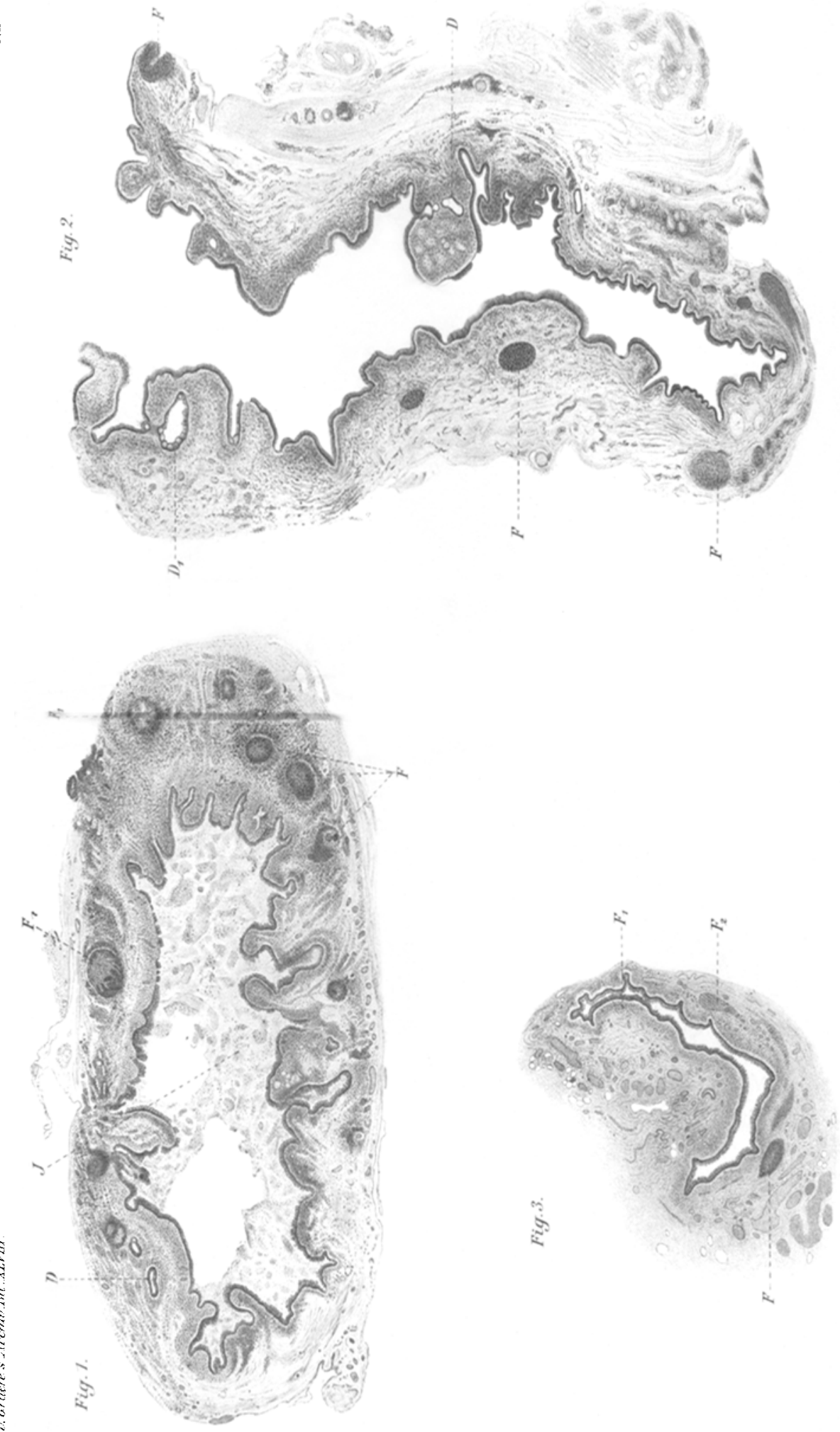


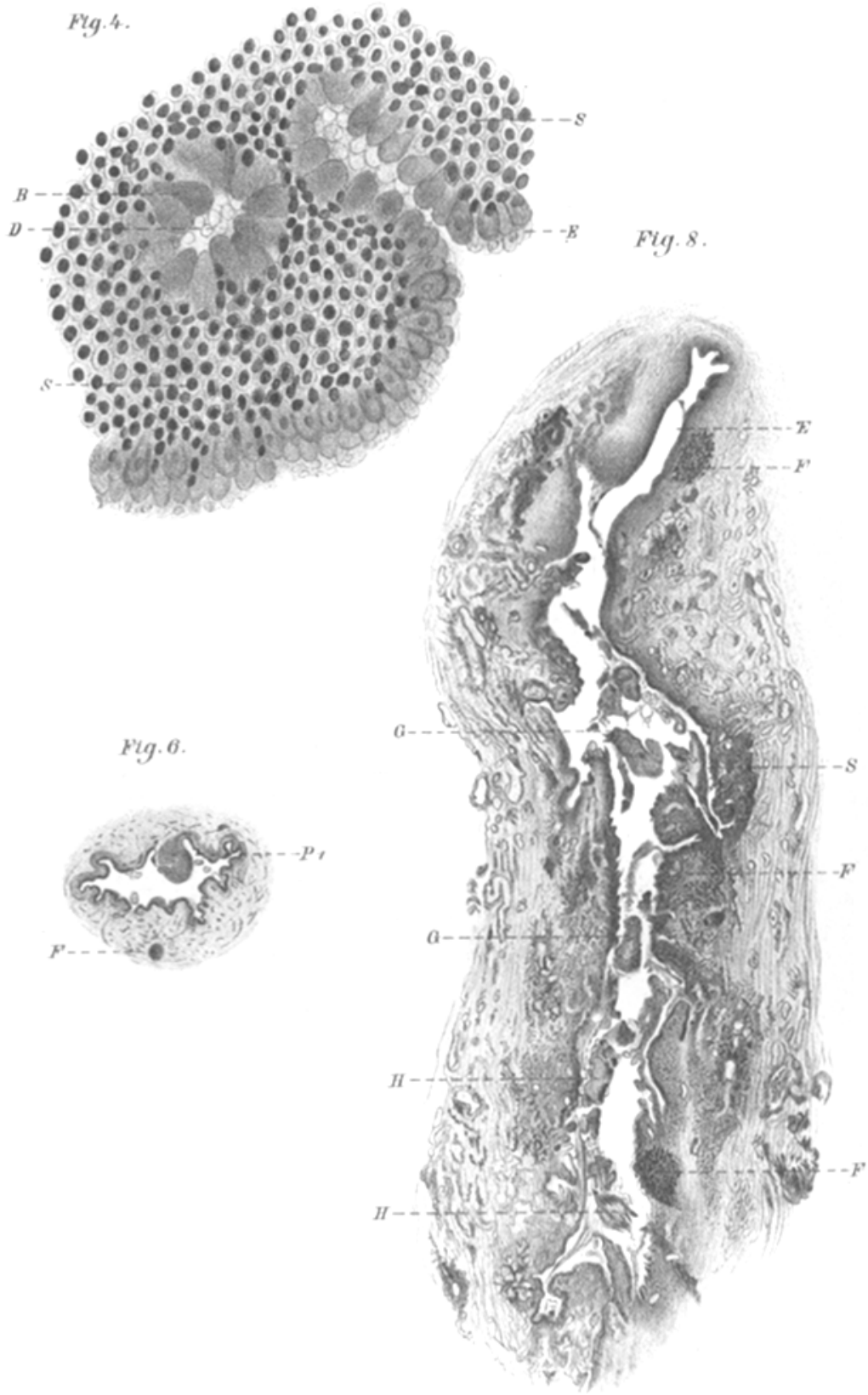


rat: $/ L$

\section{Fig. 5.}

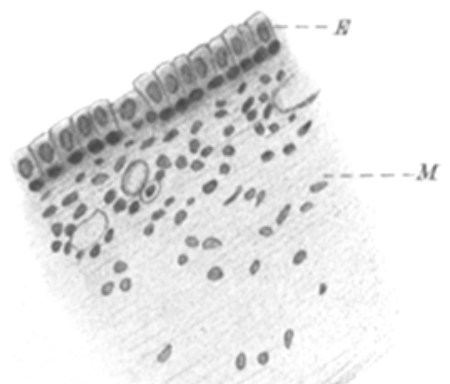

Fig. 9.

Fig. 7.
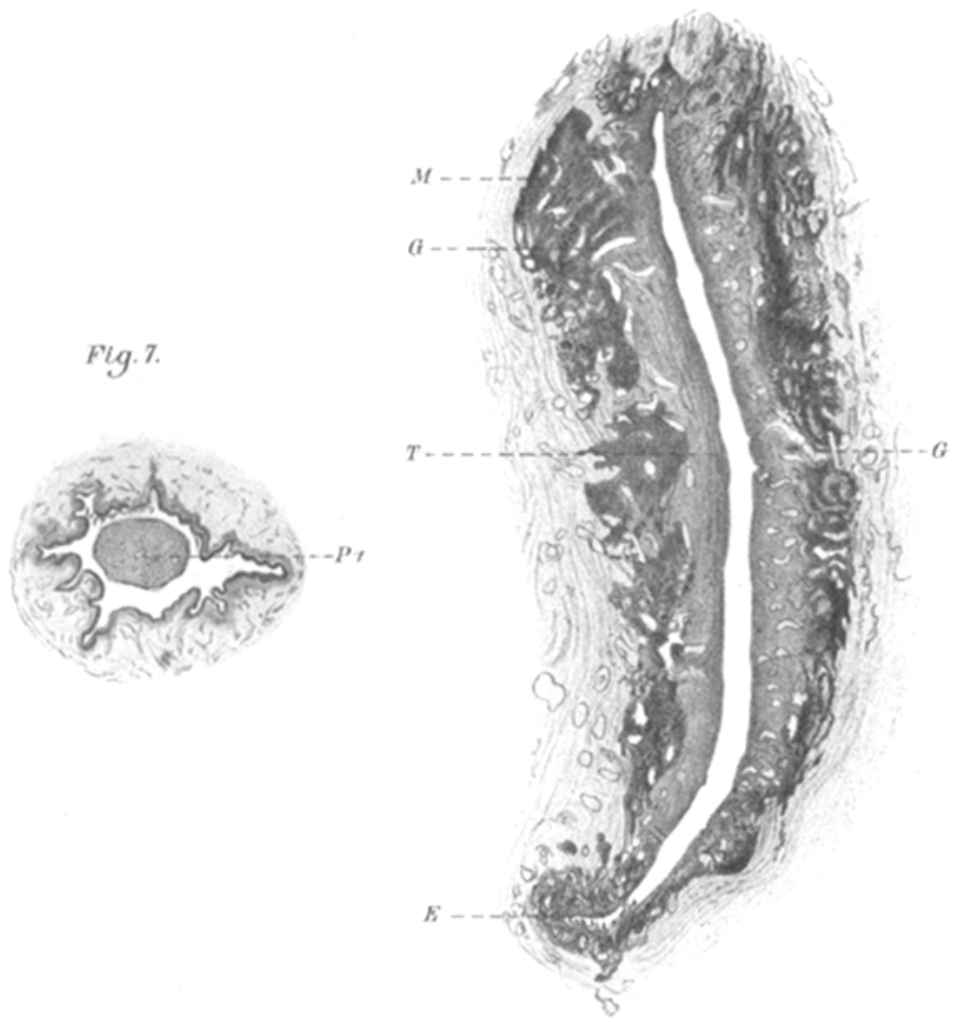